\title{
The Role of Morphological Awareness in Listening Comprehension of Chinese Blind Children: The Mediation of Vocabulary Knowledge
}

\author{
Ruibo $X i e^{1,2}$ \\ Yue Xia ${ }^{1,2}$ \\ Xinchun $\mathrm{Wu}^{3}$ \\ Ying Zhao ${ }^{3}$ \\ Hongjun Chen (D) $^{3}$ \\ Peng Sun ${ }^{3}$ \\ Jie Feng ${ }^{3}$
}

'Parents Education Research Institution, College of Teacher Education, Zhejiang Normal University, Jinhua, People's Republic of China; ${ }^{2}$ Key Laboratory of Intelligent Education Technology and Application of Zhejjiang Province, College of Teacher Education, Zhejiang Normal University, Jinhua, People's Republic of China; ${ }^{3}$ Research Center of Children's Reading and Learning, Beijing Key Laboratory of Applied Experimental Psychology, Faculty of Psychology, Beijing Normal University, Beijing, People's Republic of China
Correspondence: Xinchun Wu Research Center of Children's Reading and Learning, Beijing Key Laboratory of Applied Experimental Psychology, Faculty of Psychology, Beijing Normal University, Beijing, People's Republic of China

Email xcwu@bnu.edu.cn
Background: Listening comprehension is particularly important in children without sight. Little research has focused on listening comprehension. There are strong correlations among syllables, morphemes, and orthographic representations in Chinese. For this reason, vocabulary knowledge may have a mediating role in morphological awareness and listening comprehension in blind children during the elementary school.

Methods: The study that included measures of children's age, working memory, rapid automatized naming, phonological awareness, morphological awareness, vocabulary knowledge, and listening comprehension was administered to 142 Chinese-speaking blind children during the early elementary level (Grades 1 to 3 ) and late (Grades 4 to 6). Through a mediation analysis following the bootstrapping procedures.

Results: The study shows that (1) morphological awareness predicted listening comprehension in blind children directly; (2) after children's age, working memory, rapid automatized naming, and phonological awareness controlled, vocabulary knowledge plays a mediating role in morphological awareness and listening comprehension.

Conclusion: The findings of the present study indicate the important unique role of morphological awareness and the mediation of vocabulary knowledge in blind children's listening comprehension during the elementary school years.

Keywords: morphological awareness, vocabulary knowledge, listening comprehension, blindness, Chinese

\section{Instruction}

Listening comprehension is the first kind of speech activity a child acquires and is critical for language interactions and literacy acquisition, and it is significant for daily communication. ${ }^{2,3,10,28}$ With the prevalence of PCs and smartphones and the growing use of apps, audiobooks have been advancing rapidly and are used increasingly commonly in blind children, which allows them to more easily obtain information by listening than Braille reading. For blind children, yet relatively little is known about the variables contributing to listening comprehension in primary school.

Listening comprehension refers to the 'ability to listen and comprehend spoken language of multiple utterances and oral texts', ${ }^{28}$ it is a complex process in which a range of cognitive and linguistic skills are involved and depends on the same general semantic components that are involved in text comprehension. ${ }^{19,26,27}$ The level of text comprehension reflects the degree to which the visually impaired 
students decode, extract and construct meanings of information. ${ }^{47}$ At present, there is no consistent conclusion about the comparison of the level of text comprehension between the visually impaired students and normal students with eyesight, but the visually impaired students seem to have made greater progress in text comprehension. ${ }^{12,14,34,37}$ Many scholars and researchers have been very concerned about the role of specific cognitive and linguistic skills - morphological awareness (ie, explicit knowledge of how words are built up by combining smaller meaningful units), ${ }^{5}$ and vocabulary knowledge (ie, understanding a word's meaning across a variety of contexts) in reading comprehension, but not listening comprehension. However, despite the importance of listening comprehension in literacy acquisition and language interactions, ${ }^{2,28,29}$ few studies have examined the role of morphological awareness and vocabulary knowledge development of listening comprehension of blind children. $^{21,27,58}$ Therefore, the present study aimed to analyze the role of morphological awareness in text listening comprehension in Chinese blind children, after accounting for other cognitive and oral language skills such as working memory, rapid naming, and phonological awareness.

Morphological awareness (MA) refers to "the ability to reflect upon and manipulate morphemes and employ word formation rules in one's language". 31 As important coderelated skills, morphological awareness was found to be a unique contribution to reading comprehension across languages, ${ }^{9,49}$ especially in Chinese. ${ }^{8,32}$ Chinese is an ideographic writing, a symbol system that uses symbolic symbols to record text information. There are strong "oneto-one-to-one"correlations among syllables, morphemes, and characters. For example, the character 包 represents the morpheme bag and the syllable bāo in Chinese. ${ }^{13,38}$ Morpheme is the smallest meaningful or consistently occurring element in a language, which is often conditioned phonologically and morphologically by the relevant elements. It can be combined to form a word in three ways, including inflection, derivation, and compounds. ${ }^{31}$ In Mandarin Chinese, more than $70 \%$ of words are compounds, and very few inflectional and derivational words exist in Chinese. ${ }^{43}$ Chinese lexical compounding awareness, that is, "the understanding of how morphemes can be combined sensibly in the Chinese language". ${ }^{32}$ Children become aware of morphological structure in the preschool years and directly tap the ability to use both the morphemes and their morphological structure knowledge to produce new and complex words. ${ }^{23}$ Thus, compounding awareness could help children to take in the meanings of novel and complex words within texts thereby helping them to understand the meaning of the whole passage. ${ }^{61}$ Notably, morphological awareness shares characteristics with phonological and orthographic awareness, syntactic awareness (the morphological structure of words is often conditioned by syntactic context), and semantic knowledge in Chinese. ${ }^{32}$ Extensive research showed that morphological awareness was a stronger correlate of reading comprehension than phonological awareness in Chinese. ${ }^{49}$ Listening and reading comprehension abilities facilitate each other's development across years in young learners, and listening comprehension contributed to reading comprehension and this contribution increased with age. ${ }^{36,64}$ Therefore, it can be speculated that morpheme awareness may have a significant effect on listening comprehension in blind children.

Intuitively, children's vocabulary would be needed to represent words in the text, their subsequent derivation of text base representation. ${ }^{29,34}$ The rate of learning meanings for words increases rapidly during the second and third years of life, and productive vocabulary size during this time is developmentally related to grammatical and literacy skills. ${ }^{54}$ According to the Lexical Quality Hypothesis, grammatical information about word classes is a component of vocabulary knowledge and is therefore related to reading comprehension. ${ }^{46}$ Studies have increasingly found vocabulary knowledge to be one of the best predictors of reading comprehension ${ }^{35,48}$ and listening comprehension. ${ }^{16,27,53}$ Kendeou et al study showed that the correlation of children's receptive vocabulary with narrative listening comprehension was 0.41 and 0.48 for 4-6 years old, respectively. In a cross-sectional study of typically developing children, researchers found that receptive vocabulary was associated with listening comprehension among 4-5 years old. ${ }^{17}$ In a longitudinal study, Sénéchal et al reported that children's performance on receptive vocabulary tests in kindergarten explained $8 \%$ of the unique variance in listening comprehension at grade 1 after controlling for children's age, parent literacy, and other linguistic factors. In addition, the vocabulary knowledge that children learn from spoken language is far greater than that from text, ${ }^{45,57}$ the vocabulary knowledge acquired in spoken language is mainly acquired through sound, as well as listening comprehension. Therefore, vocabulary knowledge may play a role in promoting Chinese listening comprehension in blind children. 
Researchers contend that the relations between morphological and reading are complex and that these relations might be mediated by vocabulary skills. ${ }^{40,41}$ Specifically, morphological leads to increased breadth and depth of word knowledge, which in turn affects reading comprehension. By way of illustration, if a reader confronts an unfamiliar word in the text (eg, 钱包 / qiánbāo/' wallet), this reader could infer the meaning of hypothermia from its parts, such as “钱 /qián/ money” or “包 /bāo/ bag”. Recognition of the morphological structure of this vocabulary should aid a reader in interpreting and learning new vocabulary. Landi demonstrated that lowerlevel skills, such as decoding, could be dissociated from higher-order skills, such as vocabulary. That is possible because the meaning of so many English words could be predicted by their word structure, ${ }^{39}$ and awareness of morphological structures of words is believed to play an important role in vocabulary growth, ${ }^{6}$ which in turn affects reading comprehension. ${ }^{41}$ Yet these studies proposed only the possibility of the mediating role of vocabulary in influencing the relationship between morphological awareness and reading comprehension. There is limited empirical evidence from the existing literature to support this mechanism in listening comprehension, especially for blind children. The present study extends the evidence in this line of research by examining whether the relation between morphological awareness and listening comprehension is mediated by vocabulary knowledge in blind children.

It is worth noting that children's morphological awareness, vocabulary knowledge, and reading comprehension significantly increases with the onset of literacy and formal education in elementary school, ${ }^{23,56}$ as well as listening comprehension. ${ }^{28}$ In Chall's model of reading, children apply bottom-up or text-based strategies in stages one and two (grades 1-3), but stage three (grades 4-6) is marked by children employing top-down or reader-based decoding strategies as they shift from "learning to read" to "reading to learn", which could also be extended to blind children. ${ }^{56}$ Compared with children with normal vision, visually impaired children lack the intuitive visual information stimulation of word in language learning. But the use of Braille and audiobooks can also help children acquire morpheme awareness and vocabulary knowledge to a large extent, thereby promoting listening comprehension. Therefore, Chall's model may also be extended to blind children. Nevertheless, little is known about how the roles of morphological awareness, vocabulary knowledge in listening comprehension develop in Chinese blind children. Morphological awareness and vocabulary knowledge continue to improve for a long period as well as blind children changes from "learning to read" to "reading to learn" during elementary school, ${ }^{56}$ it stands to reason that morphological awareness and vocabulary knowledge would promote listening comprehension would be longlasting. Therefore, it is very necessary to clarify the role of morphological awareness and vocabulary knowledge in listening comprehension at different stages of development, especially in the early and late elementary school years, respectively.

Several control variables, such as children's age, working memory, rapid automatized naming, and phonological awareness, were included in our study to minimize the possibility that any observed relationships are due to extraneous variables. If children do not have the adequate memory capacity to hold words and sentences while processing their meanings, they will not be able to perform well in any language tasks and listening comprehension. ${ }^{11,15}$ Additionally, rapid automatized naming represents a critical aspect of the "cognitive foundation" of children's reading acquisition. ${ }^{1}$ In print reading, studies show that rapid naming is highly correlated with reading ability. ${ }^{20}$ Phonological awareness is strongly related to the acquisition of word decoding skills, as it allows children to segment the sounds of words and then master letter-sound correspondences. ${ }^{14}$ A series of studies have found that phonological awareness is highly related to reading comprehension in blind children. ${ }^{22,59,60}$ Therefore, with these variables being controlled to minimize the bias from extraneous variables, the present research aimed to investigate the unique role of semantic components in listening comprehension for Chinese blind children across elementary grades.

As one of the necessary component skills in reading, listening comprehension is critical for blind children's language interactions and literacy acquisition. Reading instruction for blind children is and has been of major concern in the research literature. ${ }^{50,51}$ Listening comprehension instruction also is an integral part of reading and writing instruction, incorporating these multiple languages and cognitive skills. To our knowledge, no previous studies have examined whether morphological awareness and vocabulary knowledge are related to listening comprehension in blind children. If such relationships exist, we conclude that these components should be incorporated into existing reading comprehension instruction for blind 
children, given that these linguistic skills are malleable. ${ }^{28}$ The present study aims to examine the unique role of morphological awareness and vocabulary knowledge in blind children's text listening comprehension from the early (Grades 1-3) and late (Grades 4-6) elementary school years. If so, we will further examine whether morphological awareness is directly related to listening comprehension or indirectly related to listening comprehension via vocabulary, after other cognitive and linguistic factors were controlled.

\section{Materials and Methods Participants}

The relevant Research Ethics committee of Beijing Normal University approved this study. Written informed consent was obtained from the parents of all of the children before the study. Typically, visually impaired students are placed in special schools in China. These schools cater to both low-vision and blind students. Most low-vision students cannot print read even with eyesight-aiding devices, and only Braille is used in teaching and learning. One hundred and forty-two blind students were recruited from two urban special schools in the Hunan and Zhejiang provinces of China. Specifically, the blind participants consisted of 11 children ( 8 males) in grade 1, 24 children (13 males) in grade 2, 22 children (15 males) in grade 3, 24 children (13 males) in grade 4, 24 children (13 males) in grade 5, and 48 children (24 males) in grade 6. All students were native speakers of Chinese and had normal hearing and intelligence based on feedback collected from teachers and parents. To investigate developmental patterns, the blind participants comprised two groups: (1) blind children in lower grades of primary school, including 57 blind students across grades 1 to 3 (mean age $=131.39$ months), two of whom still perceive light, but the others have no remaining rest vision; and (2) blind children in higher grades of the primary school including 85 blind students across grades 4 to 6 (mean age $=172.47$ months), three of whom do still perceive light, whereas the others have no remaining rest vision.

\section{Measures}

A battery of measures, including working memory, rapid automatized naming, phonological awareness, morphological awareness, vocabulary knowledge, and text listening comprehension was administered to the children in the fall semester. All measures in the study has been verified.
Except for the text listening comprehension test, all other measures were administered individually. The order of test administration was random across classrooms. All measures were administered by trained experimenters who were graduate students majoring in psychology or education. To avoid fatigue, data collection was completed over one week. The testing of morphological awareness, vocabulary knowledge, and text listening comprehension, lasted for approximately 30 to 35 minutes, and the other two lasted for approximately 5 to 10 minutes.

\section{Text Listening Comprehension}

Text listening comprehension was measured with narrative essay listening. There were four narrative stories composed of 178, 331, 320, and 440 words respectively. In the task, after listening to every narrative story, children were asked four single-choice comprehension questions. The questions focused on the particular words, phrases, and global topics contained in the text. A correct answer was given 1 point, and 0 points were given for an incorrect response or no response. Cronbach's $\alpha$ was 0.78 .

\section{Vocabulary Knowledge}

The vocabulary definition task was administered to assess children's vocabulary knowledge. Children were asked to produce an explanation of the words that were orally presented (eg, 客厅/ke4 - ting1/ "parlor", to which the best answer would be 'the place to meet guests'). There were 1 practice and 32 test items. Two trained psychology students based on the rating criteria rated children"s answers on a scale of $0-2$. The score two was allotted for the response that fairly completely explained the meaning of the word; the score one for an incomplete answer that partially described the meaning of the word; and the score zero for a very irrelevant explanation of the word. Testing stopped if a child failed on five consecutive items. Cronbach's $\alpha$ was 0.74 .

\section{Morphological Awareness}

This task tested children's awareness of and ability to manipulate the morphology and the morphological structure of compound words. Similar to Liu and McBrideChang's study, a question/scenario was presented orally to the children, and they were asked to say a novel word according to the meaning of the question. ${ }^{8}$ For example, one question was, “像青蛙的鸟叫什么? (What should we call a bird like a frog?)”. The best answer was 蛙鸟(/wā niăo/, frog bird). This task included two parts. The first part involved manipulating two morphemes, whereas 
the second part involved three morphemes. Two scorers rated this test at the same time. If there was a discrepancy in scoring a test term, the scorers conferred to resolve it. A scale of 0-3 was used to score the responses of the children according to two aspects: concise morphemes (e $\mathrm{g}$ 蛙 /wā/, frog and 乌 $/$ niăo/, bird) and correct word structure (conform to Chinese expression). The response that included all critical morphemes and a correct and succinct structure was worth three points. The response that included all critical morphemes and a correct but partially redundant structure was worth two points. The response that included all critical morphemes and a correct but completely redundant structure was worth one point. The response with missing critical morphemes only was worth zero points, an unrelated response, or no response. This test included 8 practice items and 20 test items. If the children did not answer five consecutive items, the test was stopped. Cronbach's $\alpha$ was 0.86 .

\section{Phonological Awareness}

The children's phonological awareness was tested with a phoneme deletion task. In the task, children were asked to produce a new syllable by removing the target phoneme from a monosyllabic Chinese word. For example, they were asked to remove the "zh" from the syllable "zhá", and the answer was "á". A correct answer was given 1 point, and 0 point were given for an incorrect response or no response. There were four practice items and 12 test items, including four initial, middle, and last phoneme deletion items. Cronbach's $\alpha$ was 0.88 .

\section{Rapid Automatized Naming (RAN)}

A rapid digit naming task used in previous research was used in this study. ${ }^{55}$ In this task, 5 digits, specifically $1,3,4,5,8$, were repeated 5 times in random order on a single sheet of paper. The children were instructed to say aloud the digits from left to right and from top to bottom as quickly and accurately as possible. Each child named the digits twice. The average latency across the two trials was computed to the nearest 1 / 100 s, and errors were recorded. Cronbach's $\alpha$ was 0.76 .

\section{Working Memory}

This study assessed children's working memory with digit short-term memory task, ${ }^{7}$ which required repetition of digits in a backward condition. Longer strings of digits were orally presented to the children at the speed of one digit per second as the task progressed. The length of digit strings ranged from 3 to 12 . There were two items for each length. The total score was 10; 0.5 point was given for each digit string correctly recalled. Cronbach's $\alpha$ was 0.87 .

\section{Analysis Strategy}

Descriptive statistics and Pearson correlations were calculated to examine the associations among working memory, RAN, phonological awareness, morphological awareness, vocabulary knowledge, and text listening comprehension in each group, respectively. To examine the unique roles of morphological awareness and vocabulary knowledge, in-text listening comprehension among blind children in early (grades 1 to 3) and late (grades 4 to 6) elementary levels, we ran hierarchical regressions for each group. In each regression analysis, children's age, working memory, RAN, and phonological awareness were entered together in the first step, while morphological awareness and vocabulary knowledge were entered in the second step, respectively.

To examine whether morphological awareness directly facilitates reading comprehension and indirectly facilitate text listening comprehension via vocabulary knowledge among blind children during the early of elementary level (Grades 1 to 3 ) and late (Grades 4 to 6), after children's age, working memory, RAN and phonological awareness controlled. Then, we performed a mediation analysis following the bootstrapping procedures as outlined by Preacher and Hayes and as elucidated in Zhao et al.

\section{Results \\ Descriptive Statistics and Correlations}

Table 1 shows the means and standard deviations of all measures. All measures were presented as raw scores, except for RAN, which was calculated in seconds. Generally, the performance of the senior group on all measures was better than the junior group. The correlation analysis results (as described in Table 2) showed that the relations between morphological awareness, vocabulary knowledge text listening comprehension, and some control variables were all significant in the high and low grades group, which provides evidence to support the claim of a contribution from semantic components to listening comprehension in blind children.

The Unique Contribution of Morphological Awareness and Vocabulary Knowledge in Listening Comprehension Multiple linear regression analyses were carried out to examine whether morphological awareness and 
Table I Means, Standard Deviations, and Pearson Correlations of All Measures of the Variables

\begin{tabular}{|l|l|l|l|l|l|l|l|l|l|}
\hline Variables & $\mathbf{M}(\mathbf{S D})$ & $\mathbf{I}$ & $\mathbf{2}$ & $\mathbf{3}$ & $\mathbf{4}$ & $\mathbf{5}$ & $\mathbf{6}$ & $\mathbf{7}$ & $\mathbf{M}$ (SD) \\
\hline I. Text Listening & $8.46(3.44)$ & - & $0.43^{* *}$ & $0.43^{* *}$ & 0.19 & -0.07 & $0.38^{* *}$ & $-0.24^{*}$ & $10.64(2.91)$ \\
2. Vocabulary Knowledge & $28.54(8.96)$ & $0.54^{* *}$ & - & $0.51^{* *}$ & $0.26^{* *}$ & $0.25^{*}$ & $0.48^{* *}$ & $-0.37^{* *}$ & $37.65(10.47)$ \\
3. Morphological Awareness & $35.45(18.09)$ & $0.57^{* *}$ & $0.56^{* *}$ & - & 0.19 & -0.02 & $0.46^{* *}$ & -0.21 & $43.52(19.01)$ \\
4. Phonological Awareness & $9.68(0.76)$ & 0.24 & 0.10 & 0.09 & - & 0.05 & 0.17 & -0.16 & $9.54(0.92)$ \\
5. Age & $131.39(28.13)$ & 0.25 & $0.29 *$ & 0.14 & -0.18 & - & -0.01 & -0.04 & $172.47(20.28)$ \\
6. Working Memory & $2.47(1.47)$ & $0.40^{* *}$ & $0.30^{*}$ & 0.25 & 0.17 & $0.4 I^{* *}$ & - & $-0.38^{* *}$ & $3.57(2.04)$ \\
7. RAN & $21.52(19.55)$ & 0.07 & 0.01 & 0.11 & 0.04 & 0.11 & 0.08 & - & $16.74(6.69)$ \\
\hline
\end{tabular}

Notes: Below the diagonal for Grades I-3. Above the diagonal for Grades 4-6; $*_{p}<0.05, *_{p}<0.01$, two-tailed.

Table 2 Unique Variance in Listening Comprehension by Morphological Awareness and Vocabulary Knowledge

\begin{tabular}{|l|l|l|l|l|l|l|l|}
\hline & & \multicolumn{3}{|c|}{ Grade I-3 } & \multicolumn{3}{c|}{ Grade 4-6 } \\
\hline Step & Predicting variables & $\Delta \mathbf{R}^{\mathbf{2}}$ & $\boldsymbol{\beta}$ & $\boldsymbol{t}$-value & $\Delta \mathbf{R}^{\mathbf{2}}$ & $\boldsymbol{\beta}$ & $\boldsymbol{t}$-value \\
\hline $\mathrm{I}$ & Age & $0.17^{*}$ & 0.10 & 0.73 & $0.15^{*}$ & -0.07 & -0.70 \\
& Working Memory & & 0.36 & $2.60^{*}$ & & 0.38 & $3.69^{*}$ \\
& RAN & 0.00 & 0.03 & 0.21 & 0.01 & -0.11 & -0.97 \\
& Phonological Awareness & 0.04 & 0.22 & 1.71 & 0.02 & 0.13 & 1.27 \\
2b & Morphological Awareness & $0.23^{* *}$ & 0.50 & $4.50^{* *}$ & $0.08^{*}$ & 0.33 & $2.95^{*}$ \\
2c & Vocabulary Knowledge & $0.19 * *$ & 0.47 & $3.95^{* *}$ & $0.10^{*}$ & 0.38 & $3.32^{*}$ \\
\hline
\end{tabular}

Note: ${ }^{*} p<0.05,{ }^{* *} p<0.01$, two- tailed.

vocabulary knowledge uniquely related to variance in accuracy of listening comprehension of text in blind children, after controlling for age, working memory, and RAN (Table 2). In each regression analysis, children's age, working memory, RAN, and phonological awareness were entered together in the first step, while morphological awareness and vocabulary knowledge, were entered in the second step respectively. In the group of Grades 1 to 3 and Grades 4 to 6, morphological awareness and vocabulary knowledge all uniquely explained variance in text listening accuracy in Chinese for blind children, after being controlled for age, working memory, and RAN. The results probably showed that morphological awareness and vocabulary knowledge were all would be necessary for listening comprehension in blind children.

\section{Indirect Contributions of Morphological Awareness on Listening Comprehension}

Furthermore, to examine whether morphological awareness directly facilitates reading comprehension and indirectly facilitate text listening comprehension via vocabulary knowledge among blind children during the early of elementary level (Grades 1 to 3) and late (Grades 4 to 6), after children's age, working memory, RAN and phonological awareness controlled. Then, we performed a mediation analysis following the bootstrapping procedures as outlined by Preacher and Hayes and as elucidated in Zhao et al. In the group of Grades 1 to 3, analyses and bootstrap estimates (based on 5000 bootstrap samples) indicated that the total effect $(\beta=0.15,95 \% \mathrm{CI}=0.04-0.21)$ of the morphological awareness and vocabulary knowledge were significant. In addition to a significant direct contribution ( $\beta=0.11 ; 95 \%$ $\mathrm{CI}=0.03-0.19)$, morphological awareness made significant indirect contributions to text listening comprehension via reading vocabulary $(\beta=0.04 ; 95 \% \mathrm{CI}=0.01-0.10$; standar$\operatorname{dized} \beta=0.13)$. Furthermore, the similar results has found in the group of Grades 4 to 6 , the indirect effect through vocabulary knowledge was significant $(\beta=0.02 ; 95 \% \mathrm{CI}=0.01-$ 0.05 ; standardized $\beta=0.09$ ), besides a significant direct contribution $(\beta=0.05 ; 95 \% \mathrm{CI}=0.02-0.11)$. The mediation analysis indicated that vocabulary knowledge partially mediated the impact of morphological awareness on text listening comprehension in the group of Grades 1 to 3 and Grades 4 to 6 , respectively.

\section{Discussion}

The present study aimed to refine our understanding of the relative strength of direct and indirect contributions of morphological awareness to text listening comprehension among blind children in early and late primary schools. 
The findings from this study have three main implications for understanding the listening comprehension development of blind children. First, to our knowledge, this was the first time to found that the effects of morphological awareness may be an extremely important influence factor for text listening comprehension among blind children in the early (Grades 1 to 3 ) and late (Grades 4 to 6 ) elementary school years. In addition, the unique contribution of morphological awareness to listening comprehension remains significant after controlling for age, working memory, RAN, and phonological awareness. Second, our results converge with prior studies in highlighting the important role of vocabulary knowledge in text listening comprehension for normal children, ${ }^{17,18,53}$ and expand the previous research by finding that the predictive power of vocabulary knowledge continues in the early and late elementary school years for blind children. Third, our results converge with prior research conducted with normal children in vocabulary definitions as a powerful mediator of the relationship between morphological awareness and reading comprehension extend this finding to test listening comprehension for blind children. ${ }^{7,8}$ Together, these findings contribute to a more complete view of the multiple direct and indirect roles that morphological awareness may play in text listening comprehension for blind children in the early and late elementary school years.

After age, working memory, RAN and phonological awareness were controlled, results found that blind children's morphological awareness plays a unique role in text listening comprehension during the early (Grades 1 to 3 ) and late (Grades 4 to 6). Due to the productivity of compound words in Chinese, and most words have meanings that can be inferred from their morphemes. ${ }^{31}$ When faced with unknown or morphologically complex words in listening, morphological awareness might help children extract familiar morphemes and understand the combination of the morphemes in words, then children might be able to reasonably deduce the meaning of unknown or morphologically complex words, thereby fostering understanding of the gist of a text or dialogue. In addition, the study also found that morphological awareness may be a direct predictor of text and dialogue listening comprehension development throughout the primary school years. Kuo and Anderson pointed out that 'morphological awareness becomes an increasingly important predictor of measures of reading as children grow older (p. 161). According to phase theories of reading development, children's reading is developing and changing during elementary school. Many researchers pointed out that text listening comprehension is similar to reading comprehension. ${ }^{16,18,25,42}$ Thus, the present results showed that the contribution of morphological awareness to text listening comprehension tends to last for a long period in primary school. Therefore, it is unsurprising that morphological awareness is important for listening comprehension.

Concerning vocabulary knowledge, our results show that the complexity of the semantic representations of words and their organization into a semantic system affect listening comprehension of text both in grades 1 to 3 and grades 4 to 6 , after children's age, working memory, RAN and phonological awareness were controlled for. Because spoken words function as principal carriers for meaning, knowledge of word meanings accounts for listening comprehension. ${ }^{44}$ This study showed that better knowledge of word meanings contributes to concurrent listening comprehension, similar to findings in previous research. ${ }^{18,27,53}$ Sénéchal et al reported that children's performance on receptive vocabulary tests in kindergarten explained $8 \%$ of the unique variance in listening comprehension in grade 1 after controlling for children's age, parent literacy, and other linguistic factors. Moreover, Kendeou et al also found similar results. In particular, vocabulary knowledge was consistently associated with listening comprehension scores across the different grades, suggesting that text and dialogue listening require children to draw considerably on their vocabulary knowledge. The results of this study shed light on the predictive role of vocabulary knowledge in Chinese listening comprehension for blind children in elementary school.

Findings from the current study converge with common theoretical arguments suggesting that an important role for morphological awareness involves the broadening of students' reading vocabulary, ${ }^{31,52}$ which in turn yields a broader repertoire of word meanings for extracting meaning from text. In the present study, the indirect contribution of morphological awareness to listening comprehension via vocabulary knowledge was found to be statistically significant in the group of Grades 1 to 3 and Grades 4 to 6 for blind children, after students' age, working memory, RAN, phonological awareness controlled. This finding also supports Nagy's metalinguistic hypothesis, which theorizes that morphological awareness, as one aspect of metalinguistic awareness, contributes to the reading comprehension process beyond its role in vocabulary acquisition. Morphological 
awareness refers to the ability to identify, analyze, and manipulate the morphological structure rules in a word, ${ }^{33}$ facilitate the accurate, rapid reading of words or connected text, thus freeing attentional resources for comprehension. ${ }^{5}$ The automaticity theory ${ }^{31}$ can explain the potential mediation of word reading between morphological awareness and reading comprehension across languages, including English, ${ }^{9,24}$ and Chinese. ${ }^{7,8,62}$ Yeung et al found that morphological awareness had significant indirect effects on reading comprehension via word reading accuracy in fourth graders in Hong Kong. A longitudinal mediation analysis revealed that word reading partially mediated the relationship between morphological awareness and reading comprehension in Chinese children. ${ }^{7}$ Previous studies have identified the role of morphological awareness in reading comprehension. ${ }^{8,63}$ The present study extends this line of research by demonstrating the relationship between listening comprehension and blind children who are very dependent on listening.

The present study has some clear limitations. This study did not assess verbal IQ, which has been controlled for in other studies of text comprehension. ${ }^{4}$ It is possible that other factors not included in this study contributed to the development of children's narrative listening comprehension, such as children's comprehension monitoring and theory of mind. ${ }^{28,30}$ These factors should be considered in future studies. A cross-sectional study design was used in this study, which does not permit strong conclusions about cause-and-effect relationships between morphological awareness and listening comprehension but is useful for initial exploratory investigations in blind children.

Even with these limitations, however, the findings make important contributions to research and practice. First, the investigation of the role of morphological awareness in the development of Chinese blind children's listening comprehension is a further novel contribution of the present study. As we all know, the present study may be the first time to investigate blind children's morphological awareness and its unique role in listening comprehension throughout elementary school years after substantive controls. The findings of the study highlight blind children's morphological awareness promotes listening comprehension. Finally, the findings have important implications for instructional practices in blind children's early development of listening comprehension, and therefore should help them consistently improve their language and academic development. Listening comprehension instruction also is and has been an integral part of reading and writing instruction, incorporating these multiple languages and cognitive skills. The outcomes of the present investigation have important implications because they may better inform educational and practical activities by identifying components that might benefit from training to foster text comprehension in blind children. Our findings suggest that morphological awareness, vocabulary knowledge predict text listening comprehension during elementary school years. Given that these linguistic skills are malleable ${ }^{28}$ these components should be incorporated into existing reading comprehension instruction for blind children. Our results emphasize the importance of practices aimed at improving blind children's ability to access and use his/her prior morphological awareness and vocabulary to understand oral texts.

\section{Funding}

Fund project information: the Key Research Base of Philosophy and Social Sciences Planning of Zhejiang Province (Children's Literature Research Center, 20JDZD060), the Major Project of the National Social Science Fund of China (13\&ZD188), the Key Laboratory of Intelligent Education Technology and Application of Zhejiang Province, Zhejiang Normal University (JYKF21007), and the Ministry of Education Humanities and Social Sciences Research Youth Fund Project (19YJC880122).

\section{Disclosure}

The authors report no conflicts of interest for this work.

\section{References}

1. Araújo S, Reis A, Petersson KM, Faísca L. Rapid automatized naming and reading performance: a meta-analysis. $J$ Educ Psychol. 2015;107 (3):868-883. doi:10.1037/edu0000006

2. Berninger VW, Abbott RD. Listening comprehension, oral expression, reading comprehension, and written expression: related yet unique language systems in grades 1, 3, 5, and 7. J Educ Psychol. 2010;102 (3):635. doi:10.1037/a0019319

3. Bree ED, Zee M. The unique role of verbal memory, vocabulary, concentration and self-efficacy in children's listening comprehension in upper elementary grades. First Lang. 2021;41:129-153. doi: $10.1177 / 0142723720941680$

4. Cain K, Oakhill J. The nature of the relationship between comprehension skill and the ability to tell a story. Br J Dev Psychol. 2011;14 (2):187-201. doi:10.1111/j.2044-835X.1996.tb00701.x

5. Carlisle JF. Awareness of the structure and meaning of morphologically complex words: impact on reading. Reading Writing. 2000;12 (3):169-190. doi:10.1023/A:1008131926604

6. Carlisle JF, Fleming J. Lexical processing of morphologically complex words in the elementary years. Sci Stud Reading. 2003;7(3):239-253. doi:10.1207/S1532799XSSR0703_3

7. Cheng Y, Li L, Wu X. The reciprocal relationship between compounding awareness and vocabulary knowledge in Chinese: a latent growth model study. Front Psychol. 2015;6:440. doi:10.3389/ fpsyg.2015.00440 
8. Cheng Y, Zhang J, Li H, et al. Growth of compounding awareness predicts reading comprehension in young Chinese students: a longitudinal study from grade 1 to grade 2. Read Res Q. 2017;52 (1):91-104. doi:10.1002/rrq.155

9. Deacon SH, Kieffer MJ, Laroche A. The relation between morphological awareness and reading comprehension: evidence from mediation and longitudinal models. Sci Stud Reading. 2014;18(6):432-451. doi:10.1080/10888438.2014.926907

10. Dickinson DK, Golinkoff RM, Hirsh-Pasek K. Speaking out for language: why language is central to reading development. Educ Res. 2013;39(4):305-310. doi:10.3102/0013189X10370204

11. Dufva M, Niemi P, Voeten MJM. The role of phonological memory, word recognition, and comprehension skills in reading development: from preschool to grade 2. Read Writ. 2001;14(1):91-117. doi:10.1023/A:1008186801932

12. Dodd B, Conn L. The effect of Braille orthography on blind children's phonological awareness. J Res Read. 2010;23(1):1-11. doi:10.1111/1467-9817.00098

13. Dulay KM, Law SY, McBride C, Ho C. Reciprocal effects of morphological awareness, vocabulary knowledge, and word reading: a cross-lagged panel analysis in Chinese. J Exp Child Psychol. 2021;206:105100. doi:10.1016/j.jecp.2021.105100

14. Edmonds C, Pring L. Generating inferences from written and spoken language: a comparison of children with visual impairment and children with sight. $\mathrm{Br} J$ Dev Psychol. 2011;24(2):337-351. doi:10.1348/026151005X35994

15. Florit MR, Chiara Levorato M, Levorato MC. Listening text comprehension of explicit and implicit information in preschoolers: the role of verbal and inferential skills. Discourse Process. 2011;48 (2):119-138. doi:10.1080/0163853X.2010.494244

16. Florit E, Cain K. The simple view of reading: is it valid for different types of alphabetic orthographies? Educ Psychol Rev. 2011;23 (4):553-576. doi:10.1007/s10648-011-9175-6

17. Florit E, Roch M, Altoè G, Levorato MC. Listening comprehension in preschoolers: the role of memory. Br J Dev Psychol. 2011;27 (4):935-951. doi:10.1348/026151008X397189

18. Florit E, Roch M, Levorato MC. Listening text comprehension in preschoolers: a longitudinal study on the role of semantic components. Read Writ. 2014;27(5):793-817. doi:10.1007/s11145013-9464-1

19. Fong CY, Ho C. What are the contributing cognitive-linguistic skills for early Chinese listening comprehension? Learn Individ Differ. 2017;59:78-85. doi:10.1016/j.lindif.2017.08.001

20. Georgiou GK, Parrila R, Cui Y, Papadopoulos TC. Why rapid automatized naming is related to reading? J Exp Child Psychol. 2013;115 (1):218-225. doi:10.1016/j.jecp.2012.10.015

21. Gottardo A, Mirza A, Koh PW, Ferreira A, Javier C. Unpacking listening comprehension: the role of vocabulary, morphological awareness, and syntactic knowledge in reading comprehension. Read Writ. 2017;31(1):1-24.

22. Gillon GT, Young AA. The phonological-awareness skills of children who are blind. J Vis Impair Blind. 2002;96(1):38-49. doi:10.1177/ 0145482X0209600105

23. Hao M, Chen X, Dronjic V, Shu H, Anderson RC. The development of young Chinese children's morphological awareness: the role of semantic relatedness and morpheme type. Appl Psycholinguist. 2013;34(1):45-67. doi:10.1017/S0142716411000609

24. Jarmulowicz L, Hay SE, Taran VL, Ethington CA. Fitting derivational morphophonology into a developmental model of reading. Read Writ. 2008;21(3):275-297. doi:10.1007/s11145-007-9073-y

25. Tannenbaum KR, Torgesen J, Wagner RK. Relationships between word knowledge and reading comprehension in third-grade children. Sci Stud Reading. 2006;10(4):381-398. doi:10.1207/ s1532799xssr1004_3
26. Kendeou P, Bohn-Gettler C, White MJ, Broek PVD. Children's inference generation across different media. J Res Read. 2010;31 (3):259-272. doi:10.1111/j.1467-9817.2008.00370.x

27. Kendeou P, Paul VDB, White MJ, Lynch JS. Predicting reading comprehension in early elementary school: the independent contributions of oral language and decoding skills. J Educ Psychol. 2009;101 (4):765-778. doi:10.1037/a0015956

28. Kim YS, Pilcher H. What is listening comprehension and what does it take to improve listening comprehension? In: Schiff R, Joshi M, editors. Handbook of Interventions in Learning Disabilities. Springer; 2016:159-174.

29. Kim YS, Wagner RK, Lopez D. Developmental relations between reading fluency and reading comprehension: a longitudinal study from grade 1 to grade 2. J Exp Child Psychol. 2012;113(1):93-111. doi:10.1016/j.jecp.2012.03.002

30. Kinnunen R, Vauras M, Niemi P. Comprehension monitoring in beginning readers. Sci Stud Reading. 1998;2:353-375. doi:10.1207/ s1532799xssr0204_4

31. Kuo LJ, Anderson RC. Morphological awareness and learning to read: a cross-language perspective. Educ Psychol. 2006;41 (3):161-180. doi:10.1207/s15326985ep4103_3

32. Liu PD, McBride-Chang C. What is morphological awareness? Tapping lexical compounding awareness in Chinese third graders. J Educ Psychol. 2010;102(1):62-73. doi:10.1037/a0016933

33. Liu PD, McBride-Chang C, Wong T, Shu H, Wong A. Morphological awareness in Chinese: unique associations of homophone awareness and lexical compounding to word reading and vocabulary knowledge in Chinese children. Appl Psycholinguist. 2012;34:755-775. doi:10.1017/S014271641200001X

34. Lorimer J, McCall S. Braille Teaching and Learning. University of Birmingham, School of Education; 1992.

35. Muter V, Hulme C, Snowling MJ, Stevenson J. Phonemes, rimes, vocabulary, and grammatical skills as foundations of early reading development: evidence from a longitudinal study. Dev Psychol. 2004;40(5):665-681. doi:10.1037/0012-1649.40.5.665

36. Melby-Lervåg $\mathrm{M}$, Lervåg $\mathrm{A}$. Reading comprehension and its underlying components in second-language learners: a meta-analysis of studies comparing first- and second-language learners. Psychol Bull. 2014;140(2):409-433. doi:10.1037/a0033890

37. Mohammed Z, Omar R. Comparison of reading performance between visually impaired and normally sighted students in Malaysia. Br J Vis Impair. 2011;29(3):196-207. doi:10.1177/0264619611415004

38. McBride CA. Is Chinese special? Four aspects of Chinese literacy acquisition that might distinguish learning Chinese from learning alphabetic orthographies. Educ Psychol Rev. 2016;28:523-549. doi:10.1007/s10648-015-9318-2

39. Nagy WE, Anderson RC. How many words are there in printed school English? Read Res Q. 1984;19(3):304. doi:10.2307/ 747823

40. Nagy W, Berninger V, Abbott R, Vaughan K, Vermeulen K. Relationship of morphology and other language skills to literacy skills in at-risk second-grade readers and at-risk fourth-grade writers. J Educ Psychol. 2003;95(4):730-742. doi:10.1037/00220663.95.4.730

41. Nagy W, Berninger VW, Abbott RD. Contributions of morphology beyond phonology to literacy outcomes of upper elementary and middle-school students. J Educ Psychol. 2006;98(1):134-147. doi:10.1037/0022-0663.98.1.134

42. Oakhill J, Cain K. Issues of causality in children's reading comprehension. In: McNamara DS, editor. Reading Comprehension Strategies: Theories, Interventions, and Technologies. Mahwah, NJ: Lawrence Erlbaum; 2007:47-72.

43. Packard JL. The Morphology of Chinese: A Linguistics and Cognitive Approach. New York: Cambridge University Press; 2000. 
44. Pearson RR, Livezey KB, Goldstein MI. Spotted owls, barred owls, and late-successional reserves. J Raptor Res. 2007;41(6):156-161. doi:10.3356/0892-1016(2007)41[156:SOBOAL]2.0.CO;2

45. Penno JF, Wilkinson IAG, Moore DW. Vocabulary acquisition from teacher explanation and repeated listening to stories: do they overcome the Matthew effect? J Educ Psychol. 2002;94(1):23-33. doi:10.1037/0022-0663.94.1.23

46. Perfetti CA, Hart L. The lexical basis of comprehension skill. In: Gorfein DS, editor. On the Consequences of Meaning Selection: Perspectives on Resolving Lexical Ambiguity. Washington, DC: American Psychological Association; 2001:67-86.

47. Papastergiou A, Pappas V. A comparison of sighted and visually impaired children's text comprehension. Res Dev Disabil. 2019;85:8-19. doi:10.1016/j.ridd.2018.10.003

48. Roth FP, Speece DL, Cooper DH. A longitudinal analysis of the connection between oral language and early reading. J Educ Res. 2002;95(5):259-272. doi:10.1080/00220670209596600

49. Ruan Y, Georgiou GK, Song S, Li Y, Shu H. Does writing system influence the associations between phonological awareness, morphological awareness, and reading? A meta-analysis. J Educ Psychol. 2018;110:108-202. doi:10.1037/edu0000216

50. Savaiano ME. Comparison of Vocabulary Instruction Strategies for Students Who Read Braille. Dissertations \& Theses - Gradworks. Vanderbilt University; 2014.

51. Savaiano ME, Compton DL, Hatton DD. Chapter six-reading comprehension for braille readers: an empirical framework for research. Int Rev Res Dev Disabil. 2014;46:177-205.

52. Stahl SA, Nagy WE. Teaching word meanings. In: Differences in the Development of Reading Fluency. Mahwah, NJ: Erlbaum; 2006;16:32-71.

53. Sene'chal M, Ouellette G, Rodney D. The misunderstood giant: on the predictive role of early vocabulary to future reading. In: Neuman SB, Dickinson D, editors. Handbook of Early Literacy Research. Vol. 2. New York: Guilford Press; 2006:173-182.

54. Silvén M, Poskiparta E, Niemi P, Voeten M. Precursors of reading skill from infancy to first grade in finish: continuity and change in a highly inflected language. J Educ Psychol. 2007;99(3):516-531. doi:10.1037/0022-0663.99.3.516
55. Shu H, Mcbridechang C, Wu S, Liu H. Understanding Chinese developmental dyslexia: morphological awareness as a core cognitive construct. J Educ Psychol. 2006;98(1):122-133. doi:10.1037/00220663.98.1.122

56. Steinman LB, Kimbrough BT, Kimbrough BT. Developmental stages of reading processes in children who are blind and sighted. $J$ Vis Impair Blind. 2006;100(1):36-46. doi:10.1177/0145482X0 10000106

57. Suggate S, Lenhard W, Neudecker E, Schneider W. Incidental vocabulary acquisition from stories: second and fourth graders learn more from listening than reading. First Lang. 2013;33(6):551-571. doi: $10.1177 / 0142723713503144$

58. Tilstra J, Mcmaster K, Broek PVD, Kendeou P, Rapp D. Simple but complex: components of the simple view of reading across grade levels. $J$ Res Read. 2010;32(4):383-401. doi:10.1111/j.14679817.2009.01401.x

59. Veispak A, Boets B, Ghesquière P. Parallel versus sequential processing in print and braille reading. Res Dev Disabil. 2012;33 (6):2153-2163. doi:10.1016/j.ridd.2012.06.012

60. Veispak A, Boets B, Ghesquière P. Differential cognitive and perceptual correlates of print reading versus braille reading. Res Dev Disabil. 2013;34(1):372-385. doi:10.1016/j.ridd.2012.08.012

61. Xie R, Zhang J, Wu X, Nguyen TP. The relationship between morphological awareness and reading comprehension among Chinese children. Front Psychol. 2019;10. doi:10.3389/fpsyg.2019.00054

62. Yeung PS, Ho SH, Chan WO, Chung KH, Wong YK. A model of reading comprehension in Chinese elementary school children. Learn Individ Differ. 2013;25(3):55-66. doi:10.1016/j.lindif.2013.03.004

63. Wu X, Anderson RC, Li W, et al. Morphological awareness and Chinese children's literacy development: an intervention study. Sci Stud Reading. 2009;13(1):26-52. doi:10.1080/10888430802631734

64. Wong YK. Developmental relations between listening and reading comprehension in young Chinese language learners: a longitudinal study. J Psycholinguist Res. 2018;50(2):1-13.
Psychology Research and Behavior Management

\section{Publish your work in this journal}

Psychology Research and Behavior Management is an international, peer-reviewed, open access journal focusing on the science of psychology and its application in behavior management to develop improved outcomes in the clinical, educational, sports and business arenas. Specific topics covered in the journal include: Neuroscience, memory and decision making; Behavior modification and management; Clinical applications; Business and sports performance management; Social and developmental studies; Animal studies. The manuscript management system is completely online and includes a very quick and fair peer-review system, which is all easy to use. Visit http://www. dovepress.com/testimonials.php to read real quotes from published authors. 